\title{
A percepção da profundidade ou relevo da máscara côncava e convexa
}

Esther Sampaio Santos. Brock University.

Lívia da Silva Bachetti. Universidade de São Paulo.

Maria Amélia Cesari Quaglia. Universidade Federal de São João Del-Rei.

Caio Rafael Silveira. Centro de Referência de Assistência Social (Baependi - MG).

Branda Garcia da Silva. Centro de Referência de Assistência Social (Baependi - MG).

\section{Resumo}

Investigou-se a percepção monocular da profundidade ou relevo de máscaras policromadas objetivas côncava e convexa. Participaram do estudo 40 estudantes, que julgaram a profundidade ou relevo da máscara côncava e da máscara convexa. Mais da metade dos observadores, $67 \%$, realizaram ou tenderam a realizar a inversão monocular da profundidade. Quando solicitados a avaliar em centímetros a distância da ponta do nariz da máscara à sua base, as maiores extensões foram designadas à máscara convexa, comparativamente à côncava. Porém, a inversão visual da profundidade de concavidades não foi afetada pela posição de apresentação das máscaras (vertical ou invertida) ou pela direção da fonte de iluminação incidente sobre elas (de cima ou por baixo). Os resultados confirmam que, na percepção de faces, o processo de alta ordem se sobrepõe ao processo de baixa ordem e que a ilusão da máscara côncava é um instrumento eficaz na verificação da percepção de profundidade.

Palavras-chave: percepção visual; percepção de profundidade; máscaras faciais.

\begin{abstract}
The perception of depth or relief of hollow and convex face. It was investigated the monocular perception of depth or relief of objective concave and convex masks. The study included 40 students, who judge the depth or relief of a concave and a convex mask. More than half of observers, $67 \%$, performed the monocular depth inversion. When asked to evaluate the distance in centimeters from the tip of the nose to the base of the mask, the major extensions were appointed to the convex mask, compared to concave. However, the visual inversion of depth of the concavities was not affected by the position of the masks (vertical or inverted) or by the direction of the light source incident on them (from top or bottom). The results confirm that in the face perception, the top-down process overlaps the bottom-up process and that the hollow-face illusion is an effective instrument in depth perception verification.
\end{abstract}

Keywords: visual perception; depth perception; facial masks.

\section{Resumen}

La percepción de profundidad o relieve de la máscara hueca y convexa. Se investigó la percepción monocular de profundidad o relieve de máscaras huecas y convexas objetivas. En el estudio participaron 40 estudiantes que juzgaron la profundidad o relieve de máscaras huecas y convexas. Más de la mitad de los observadores, el 67\%, realizó la inversión monocular de la profundidad. Cuando se les pidió para evaluaren la distancia en centímetros desde la punta de la nariz hasta la base de la máscara, las más grandes extensiones fueron nombradas a la máscara convexa, en comparación con la máscara hueca. Sin embargo, la visual inversión de la profundidad de los huecos no ha sido afectada por la posición de presentación de las máscaras (vertical o invertida) o por la dirección de la fuente de luz incidente sobre ellas (desde arriba o abajo). Los resultados confirman que la percepción de las caras, los procesos de orden superior se superponen los procesos de orden inferior y la ilusión de la máscara hueca es una herramienta eficaz en la verificación de la percepción de profundidad.

Palabras clave: percepción visual; percepción de la profundidad; mascarillas faciales. 
Na percepção visual dos estímulos, existem dois processos que ocorrem simultaneamente: o bottom-up e o top-down. O primeiro, considerado como um processo perceptual de baixa ordem, é referente ao recebimento das informações sensoriais provindas do ambiente. Já o segundo processo, top-down, relativo à cognição, é o processamento dessas informações com base no conhecimento prévio do organismo. Em casos como no fenômeno ilusório de inversão visual da profundidade da máscara côncava, os processos cognitivos, top-down, relacionados ao conhecimento de faces, suplantam os processos perceptuais de baixa ordem, bottom-up (Gregory, 1997). As experiências do indivíduo e seu conhecimento prévio geram uma expectativa a respeito de como alguns tipos de estímulo já percebidos no passado irão se apresentar no presente. A expectativa tem, então, o poder de anular parcialmente os dados sensoriais conflitantes, impondo-se à memória daquele que percebe a máscara, uma interpretação ilusória da profundidade do estímulo. O estímulo apresentado, máscara côncava é, deste modo, percebido como uma face convexa (Gregory, 1997; Keane, Silverstein, Wang, \& Papathomas, 2013).

A ilusão da máscara côncava é um dos mais importantes exemplos de uma classe de estímulos que acarretam na percepção ilusória da inversão da profundidade (Vlajnic, Papathomas, Keane, Zalokostas, \& Silverstein, 2014). Comparada a estímulos côncavos não específicos, a máscara côncava apresenta uma maior probabilidade de ser percebida de maneira ilusoriamente convexa (Gregory, 1997). Neste fenômeno, o avesso de uma máscara facial iluminada em cima é percebido como uma face convexa, com fonte de iluminação embaixo. Isto porque acontece uma inversão na percepção visual da profundidade da máscara e uma inversão na percepção da direção da iluminação que incide sobre a máscara (Hill \& Bruce, 1993).

Alguns fatores têm sido citados como facilitadores da ilusão da máscara côncava, como: o posicionamento vertical da máscara (Hill \& Johnston, 2007; Quaglia \& Fukusima, 2015; Vlajnic et al., 2014; Yoshida, 2006), a observação do estímulo feita em condição monocular (Hill \& Bruce, 1993), a iluminação percebida por cima da cabeça (Hill \& Bruce, 1993; Hill \& Johnston, 2007; Kleffner \& Ramachandran, 1992; Quaglia \& Fukusima, 2015; Yoshida, 2006), a coloração da máscara com a tonalidade bege (Hill \& Johnston, 2007). Por sua vez, Keane et al. (2013) destacaram três fatores que contribuiriam para a ilusão da inversão de profundidade: 1) a familiaridade da configuração do objeto em relação ao observador; 2) uma textura enganosa da superfície iludindo o sistema visual e, por fim, 3) a tendência geral dos indivíduos em interpretar superfícies tridimensionais ambíguas como convexas, independente das variáveis relacionadas à textura e da familiaridade do objeto. Vlajnic et al. (2014) testaram o efeito da familiaridade e do posicionamento da máscara com estudantes em universitários e encontraram uma maior ocorrência da percepção ilusória para a máscara côncava da face humana na posição vertical. Os autores utilizaram também um objeto côncavo elipsóide e máscaras côncavas de faces marcianas com as características que foram mundialmente conhecidas como extraterrestres na década de 70.

Por outro lado, algumas pesquisas não encontraram diferenças na percepção ilusória dos observadores em função de variações nas condições de observação e nas características da máscara côncava. Quaglia e Fukusima (2009) pesquisaram os efeitos de características da face como a cor, a orientação da direção da fonte de iluminação e a posição da máscara côncava. Os participantes observaram a máscara côncava de um ponto de vista estacionário, monocularmente, sentados frente uma câmara com visor. A maioria dos participantes realizou a inversão monocular da profundidade, independente das direções da fonte de iluminação, da apresentação da máscara cinza ou policromada, e da posição da máscara. Resultados semelhantes foram encontrados para uma máscara côncava de tamanho reduzido, 10 $\mathrm{cm}$ de altura e $3 \mathrm{~cm}$ de profundidade, observada monocularmente dentro de uma caixa de madeira (Quaglia, Bachetti, \& Alves, 2014) e com estereogramas da máscara observada binocularmente (Quaglia \& Fukusima, 2015). Os julgamentos métricos e categóricos realizados por estudantes universitários não sofreram interferência significativa da cor e posicionamento da máscara, assim como da direção da fonte de iluminação, posto que a maioria dos participantes percebeu a ilusão da máscara côncava realizando a inversão binocular da profundidade. Os autores apontaram para a importância da percepção de faces tridimensionais convexas, mais familiares, ao observar a máscara côncava. Provavelmente isso ocorreu devido ao valor da percepção de faces para a vida do indivíduo e continuidade da espécie (Darwin, 1874).

Para além das investigações relacionadas às variações do estímulo e de suas condições de observação, a ilusão da máscara côncava também tem sido utilizada para investigar a função dos ramos ventral e dorsal na percepção de um objeto, o comportamento motor dirigido a este objeto e algumas condições psicopatológicas 
e comportamentais. Dentre os experimentos conduzidos para investigar a ilusão da máscara côncava na ação dirigida ao objeto pelo indivíduo, estão os estudos de Hartung, Franz, Kersten e Bülthoff (2001) e Hartung, Schrater, Bülthoff, Kersten e Franz (2005). Por meio de projeções de imagens estereoscópicas da máscara côncava e convexa, Hartung et al. (2001) encontraram que as estimativas da distância e os movimentos dos dedos dos participantes foram influenciados pela ilusão da máscara côncava. Além disso, a máscara côncava foi percebida como mais rasa do que a máscara convexa da face. Hartung et al. (2005) também investigaram a percepção visual e a ação sobre o objeto com projeções de máscaras côncava e convexa. Estes pesquisadores encontraram que, tanto as estimativas da distância entre os participantes e o estímulo, quanto os movimentos dos seus dedos em direção aos alvos localizados no interior de projeções fantasmas da máscara côncava, foram dominados pela ilusão. Ademais, as projeções da máscara côncava foram percebidas como mais planas do que as projeções da máscara convexa.

Entretanto, ainda são poucos os estudos que avaliaram a percepção da máscara côncava comparativamente com a máscara convexa. Apenas dois estudos realizam esta investigação. Em ambos, os participantes julgavam a distância egocêntrica em relação às projeções estereoscópicas das máscaras observadas binocularmente. Nenhum estudo utilizou máscaras objetivas, assim como não foram investigadas e comparadas a percepção categórica e métrica da profundidade ou relevo das mesmas. Também não foi avaliada a condição monocular de observação das máscaras côncava e convexa. Na presente pesquisa, objetivou-se investigar a inversão monocular da máscara côncava objetiva e a percepção de sua profundidade ou relevo. Objetivou-se, ainda investigar a percepção monocular da profundidade da máscara convexa, da ponta do nariz da máscara à base da sua face, comparativamente à percepção da profundidade da máscara côncava. Foram também avaliados se a posição invertida (de cabeça para baixo) das máscaras côncava e convexa e o direcionamento da fonte de iluminação (iluminada por cima e por baixo) afetam a magnitude percebida da profundidade ou relevo da máscara objetiva observada monocularmente.

\section{Método}

\section{Participantes}

A amostra foi composta por 40 voluntários, 26 mulheres e 14 homens, estudantes dos diferentes cursos de graduação e pós-graduação. Todos possuíam acuidade visual normal ou corrigida (6/6) e submeteram-se ao experimento após lerem e assinarem o Termo de Consentimento Livre e Esclarecido.

\section{Instrumentos e Materiais}

Escala Optométrica de Snellen: instrumento utilizado para a avaliação da acuidade visual dos participantes. Utilizada para a o pré-diagnóstico da acuidade visual por recomendação do Ministério da Saúde (Ministério da Saúde, 2008).

Caixa de madeira (Figura 1): utilizou-se uma caixa preta, construída com dimensões de $80 \mathrm{~cm}$ de comprimento, $37 \mathrm{~cm}$ de largura e $37 \mathrm{~cm}$ de altura. Esta caixa possuía, em uma de suas extremidades, um visor com uma abertura de $0,5 \mathrm{~mm}$ de diâmetro, para possibilitar a observação monocular da máscara disposta contralateralmente ao visor. Em seu interior foram colocadas duas lâmpadas de $7 \mathrm{w}$, posicionadas nas partes superior e inferior, para iluminar as máscara por cima e por baixo.

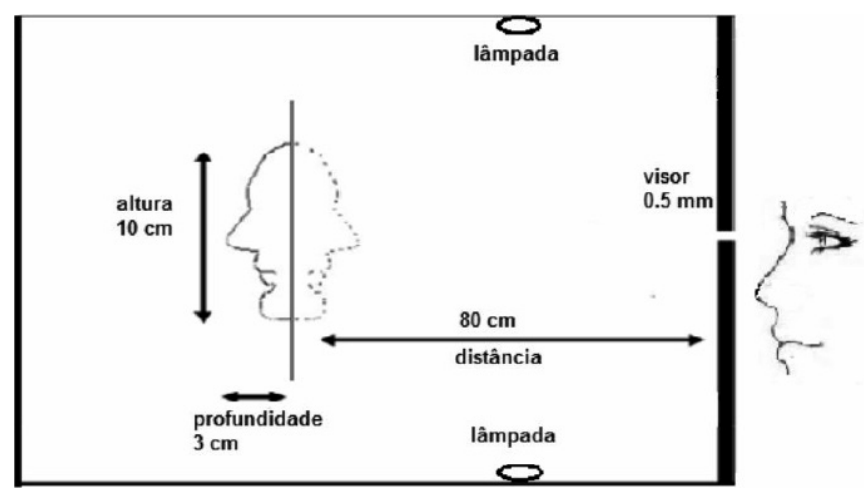

Figura 1. Figura Esquemática da Caixa Experimental de Madeira com a Máscara Côncava em Seu Interior. Fonte: Adaptação De Quaglia \& Fukusima (2009).

Máscaras da face: foram utilizadas duas máscaras de face com tamanhos reduzidos. O reverso de uma máscara, confeccionado a partir da face de uma boneca comercial, foi pintado na cor bege com detalhes faciais, como a demarcação dos olhos, boca e sobrancelhas. Utilizou-se, também, um anverso da máscara, pintado com as mesmas características do seu reverso.

Trena métrica: uma trena retrátil foi utilizada pelo observador para estimar, em centímetros, a profundidade ou relevo das máscaras côncava e convexa.

\section{Procedimento}

Inicialmente, cada participante assinou o Termo de Consentimento Livre e Esclarecido e leu as instruções. Em seguida, foi testada a sua acuidade visual, por meio da Escala Optométrica de Snellen. Esta tabela é 
padronizada e foi colocada a 6 metros de distância do observador, que demonstrou ser capaz de distinguir bem as letras impressas até a sexta linha, o que significa uma visão com boa acuidade visual (normal, 6/6). Cada olho foi avaliado separadamente e, posteriormente, foram avaliados os dois olhos juntos.

O participante foi conduzido a uma sala, onde se encontrava sobre a mesa a caixa preta experimental. 0 participante foi instruído a observar a máscara através deste visor, com o olho de sua preferência. Em ordem aleatória, a máscaras eram apresentadas nas posições vertical e invertida, iluminadas por cima e por baixo.

Em cada condição de apresentação, foi solicitado ao observador que estimasse a profundidade ou relevo percebido das máscaras em três tarefas. Na primeira tarefa, solicitou-se que julgasse se a máscara era percebida como côncava ou convexa. Esta tarefa teve por objetivo checar se o observador compreendeu a noção de concavidade e convexidade e, portanto, nenhuma análise estatística foi atribuída a essas respostas. $\mathrm{Na}$ segunda tarefa, foi solicitado que fizesse um julgamento mais preciso, atribuindo à profundidade ou relevo percebido da máscara uma das seguintes categorias ordinais: (1) muito côncava; (2) côncava; (3) plana; (4) convexa; e (5) muito convexa. Por fim, na terceira e última tarefa, foi solicitado ao observador que ajustasse, em uma trena graduada em centímetros, a distância percebida entre a ponta do nariz da máscara e a base da face da mesma. O participante teve que olhar fixamente para a máscara e depois estimar a sua profundidade ou relevo ao estender a trena em uma única tentativa. As instruções das três tarefas foram fornecidas para todas as apresentações das máscaras.

A presente pesquisa foi aprovada pela Comissão de Ética em Pesquisa Envolvendo Seres Humanos da Universidade, conforme o memorando de 20 de março de 2013, nº 024/2013/CEPES. Todos os procedimentos recomendados pela Resolução $n^{\circ}$. 196/96 foram seguidos.

\section{Resultados}

Os dados foram analisados com o software Statistical Package for Social Sciences (SPSS), versão 20.0 considerando o nível de significância de 5\%. Para realizar as análises das atribuições categóricas de profundidade ou relevo das máscaras côncava e convexa nas diferentes condições de apresentação, os dados foram agrupados de duas maneiras diferentes. Primeiramente, verificou-se a capacidade dos participantes de realizarem a inversão monocular da profundidade da máscara côncava e de detectarem corretamente o relevo da máscara convexa. Para tanto, na Tabela 1 as atribuições categóricas de concavidade ou convexidade das máscaras côncava e convexa foram reunidas em três grandes classes: côncava (categorias C1 e C2), plana (categoria C3) e convexa (categorias C4 e C5). Os dados estão dispostos em função da posição das máscaras e das duas direções da fonte de iluminação. A maioria dos participantes classificou a máscara côncava na posição vertical como convexa, percebendo a ilusão tanto para a máscara côncava iluminada por cima quanto por baixo. O mesmo pode ser observado para a máscara convexa, vertical e invertida, classificadas como "convexas" pela maioria dos observadores. Entretanto, com base na Tabela 1, nota-se que a máscara côncava posicionada de cabeça para baixo recebeu as maiores atribuições de concavidade do que quando observada na posição vertical nas duas condições de iluminação. Desta forma, a ilusão da máscara côncava foi menos proeminente quando a mesma foi apresentada na posição invertida, ocorrendo apenas em $37,5 \%$ das vezes quando iluminada por cima e em $47,5 \%$ das vezes quando iluminada por baixo. Pode-se observar ainda, na Tabela 1, que por diversas vezes tanto a máscara côncava quanto a convexa receberam a classificação "plana" nas duas condições de iluminação, por cima e por baixo. Esta classificação foi maior quando a máscara côncava foi apresentada na posição invertida e iluminada por cima, 27,5\%. Além disso, alguns observadores perceberam a máscara convexa como côncava. Essa ocorrência foi maior quando a máscara convexa foi iluminada por baixo nas posições vertical, $10 \%$, e invertida, $7,5 \%$.

Tabela 1. Frequência das Atribuições Categóricas de Profundidade ou Relevo das Máscaras Côncava e Convexa Iluminadas por Cima e por Baixo, nas Posições Vertical e Invertida.

\begin{tabular}{ccccc}
\hline Iluminação & Posição & Categoria & $\begin{array}{c}\text { Máscara } \\
\text { Côncava (\%) }\end{array}$ & $\begin{array}{c}\text { Máscara } \\
\text { Convexa (\%) }\end{array}$ \\
\hline Por cima & vertical & Côncava & 30,0 & 2,5 \\
& & Plana & 20,0 & 10,0 \\
& & Convexa & 50,0 & 87,5 \\
\multirow{2}{*}{ Por baixo } & invertida & Côncava & 35,0 & 2,5 \\
& \multirow{4}{*}{ vertical } & Plana & 27,5 & 17,5 \\
& & Convexa & 37,5 & 80,0 \\
& & Côncava & 37,5 & 10,0 \\
& & Plana & 12,5 & 2,5 \\
& Convexa & 50,0 & 87,5 \\
& \multirow{2}{*}{ invertida } & Côncava & 30,0 & 7,5 \\
& & Plana & 22,5 & 17,5 \\
& & Convexa & 47,5 & 75,0 \\
\hline
\end{tabular}


Posteriormente, como representado Tabela 2, os dados categóricos foram dispostos em cinco grandes subdivisões de classificação da intensidade da percepção: (1) muito côncava; (2) côncava; (3) plana; (4) convexa; e (5) muito convexa. A máscara côncava na posição vertical iluminada por cima foi classificada em sua maioria na categoria "convexa", 37,5\%, e quando iluminada por baixo, na categoria "muito convexa", $27,5 \%$. A maioria das atribuições para a máscara côncava invertida foi para a categoria "convexa", correspondendo a 37,5\% das ocorrências quando iluminada por cima e a $32,5 \%$ quando iluminada por baixo. Já para a máscara convexa iluminada por baixo, a atribuição "muito convexa" foi predominante, tanto na posição vertical quanto, $47,5 \%$, e na posição invertida, 40,0\%. A categoria "convexa" foi mais atribuída quando a máscara convexa foi iluminada por cima, tanto na posição vertical, $45,0 \%$, quanto na invertida, $47,5 \%$.

Tabela 2. Frequência das Atribuições Categóricas de Profundidade ou Relevo das Máscaras Côncava e Convexa Iluminadas por Cima e por Baixo, nas Posições Vertical e Invertida.

\begin{tabular}{|c|c|c|c|c|c|}
\hline & \multirow[b]{2}{*}{ Categorias } & \multicolumn{2}{|c|}{ Máscara Côncava } & \multicolumn{2}{|c|}{ Máscara Convexa } \\
\hline & & $\begin{array}{c}\text { Iluminada } \\
\text { por Cima } \\
(\%)\end{array}$ & $\begin{array}{c}\text { Iluminada } \\
\text { por Baixo } \\
(\%)\end{array}$ & $\begin{array}{c}\text { Iluminada } \\
\text { por Cima } \\
(\%)\end{array}$ & $\begin{array}{c}\text { Iluminada } \\
\text { por Baixo } \\
(\%)\end{array}$ \\
\hline \multirow{5}{*}{ : } & Muito côncava & $17,5 \%$ & $17,5 \%$ & $0,0 \%$ & $5,0 \%$ \\
\hline & Côncava & $12,5 \%$ & $20,0 \%$ & $2,5 \%$ & $5,0 \%$ \\
\hline & Plana & $20,0 \%$ & $12,5 \%$ & $10,0 \%$ & $2,5 \%$ \\
\hline & Convexa & $37,5 \%$ & $22,5 \%$ & $45,0 \%$ & $40,0 \%$ \\
\hline & Muito convexa & $12,5 \%$ & $27,5 \%$ & $42,5 \%$ & $47,5 \%$ \\
\hline \multirow{5}{*}{ 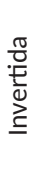 } & Muito côncava & $5,0 \%$ & $17,5 \%$ & $0,0 \%$ & $5,0 \%$ \\
\hline & Côncava & $30,0 \%$ & $12,5 \%$ & $2,5 \%$ & $2,5 \%$ \\
\hline & Plana & $27,5 \%$ & $25,0 \%$ & $17,5 \%$ & $17,5 \%$ \\
\hline & Convexa & $37,5 \%$ & $32,5 \%$ & $47,5 \%$ & $35,0 \%$ \\
\hline & Muito convexa & $0,0 \%$ & $12,5 \%$ & $32,5 \%$ & $40,0 \%$ \\
\hline
\end{tabular}

Na Figura 2 estão representadas graficamente as médias das estimativas em centímetros da profundidade ou relevo percebidos da base da face até a ponta do nariz das máscaras côncava e convexa, nas posições vertical e invertida, independente da direção da fonte de iluminação. A média global das estimativas métricas para a máscara côncava, independentemente da direção da iluminação e do seu posicionamento, foi de $2,19 \mathrm{~cm}$ $(D P=1,61)$, enquanto que para a máscara convexa foi de $2,53 \mathrm{~cm}(D P=1,86)$. Entretanto, o teste $t$ de Student para amostras dependentes não revelou diferença estatística entre essas atribuições, $t_{(159)}=-2,46$ e $p>0,05$.

Para ponderar essas estimativas métricas em função da posição das máscaras e da direção da fonte de iluminação incidente sob elas, utilizou-se o teste ANOVA de medidas repetidas ( 2 máscaras $X 2$ posições
X 2 direções de iluminação). Essa análise não encontrou efeitos principais significativos da posição $F_{(3,117)}=2,57$; $p>0,05$ e da iluminação $F_{(1,39)}=3,43 ; p>0,05$, assim como da interação entre estes dois fatores $F_{(3,117)}=1,91$; $p>0,05$ para as medidas em centímetros da profundidade ou relevo das máscaras côncava e convexa.

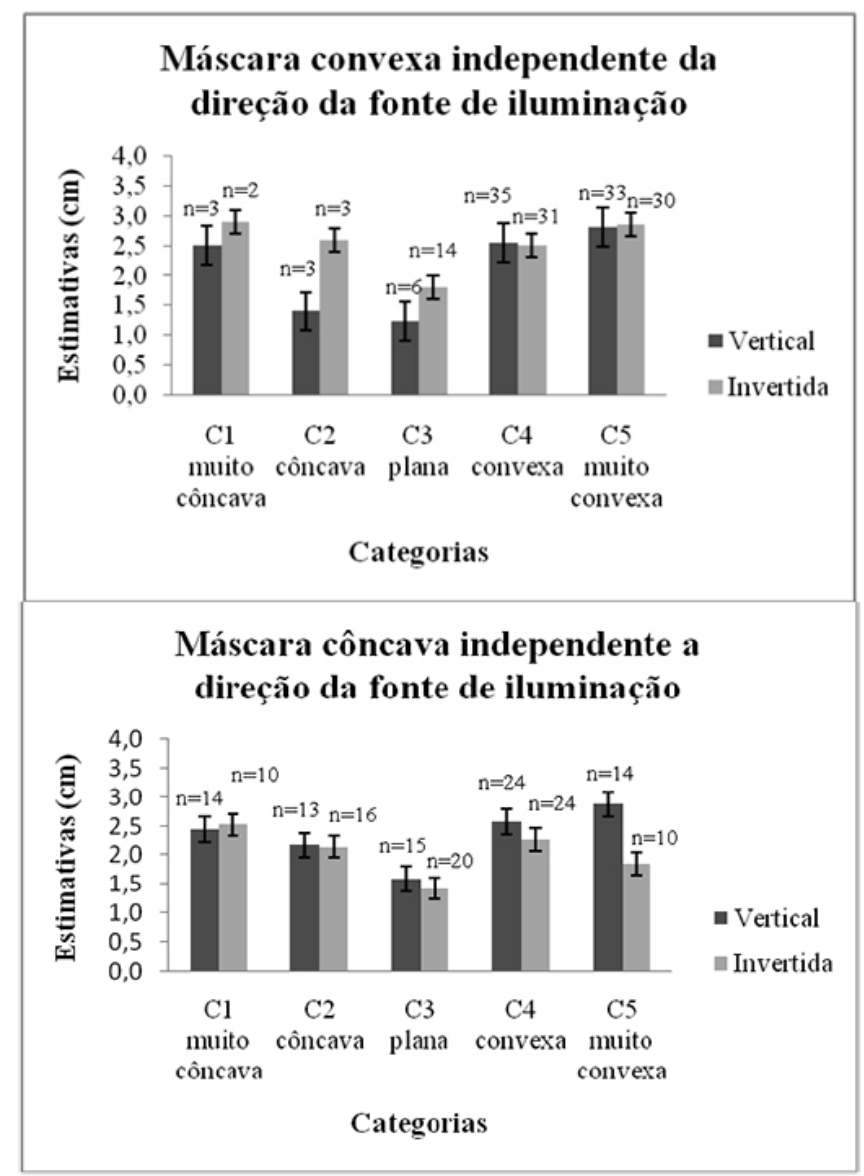

Figura 2. Média das Estimativas Métricas e Erros-Padrão da Profundidade ou Relevo das Máscaras Côncava e Convexa, nas Posições Vertical e Invertida, Independente da Direção da Fonte de lluminação. Os Valores Estão Dispostos em Função das Atribuições Categóricas Muito Côncava (C1), Côncava (C2), Plana (C3), Convexa (C4) E Muito Convexa (C5).

\section{Discussão}

A maioria dos observadores realizou a inversão monocular da profundidade da máscara côncava objetiva percebendo-a como convexa. Essa tendência dos indivíduos saudáveis em perceber a ilusão da máscara côncava é explicada pelo predomínio dos processos cognitivos, top-down, sobre os inputs sensoriais, bottom-up, provenientes do objeto real durante a percepção de concavidade (Gregory, 1997; Keane et al., 2013). A inversão visual da profundidade de concavidades tem se mostrado consistente em alguns estudos 
realizados, tanto com objetos diversos (Hill \& Johnston, 2007), quanto com máscaras objetivas da face humana (Quaglia \& Fukusima, 2009; Quaglia et al., 2014) e com projeções de estereogramas das máscaras (Hill \& Bruce, 1993; Hill \& Johnston, 2007; Hartung et al., 2005; Keane et al., 2013).

A análise das atribuições categóricas revelou uma preferência dos observadores em atribuir categorias intermediárias como moderadamente côncavas ou moderadamente convexas à sua percepção, como encontrado por Quaglia e Fukusima (2009) e Quaglia et al. (2014). Houve uma tendência dos participantes para inverter a profundidade da máscara côncava percebendo-a como plana, especialmente na condição invertida iluminada por cima (27,5\%). Curiosamente, os sujeitos perceberam a máscara convexa como côncava, principalmente quando a máscara foi iluminada por baixo independentemente de sua posição $(12,5 \%)$. Possivelmente, as máscaras côncavas e convexas utilizadas, faces de bonecas comerciais, não representassem bem a face humana, dando-lhes um aspecto além de infantil, artificial.

A direção da fonte de iluminação e a posição da máscara não exerceram interferências significativas nos julgamentos categóricos de profundidade ou relevo das máscaras côncava e convexa. Esses resultados confirmam os achados de pesquisas anteriores, onde a ilusão da máscara côncava foi predominante a despeito de diversas alterações nas características das máscaras utilizadas, como a coloração, e nas condições em que foram apresentadas: posição vertical e invertida, sob diferentes direções das fontes de luz incidente (Quaglia \& Fukusima, 2009; Quaglia et al., 2014).

Quanto às atribuições em centímetros, o posicionamento das máscaras côncava e convexa não se constituiu em um fator determinante para a percepção de sua profundidade ou relevo. Da mesma forma, as variações na direção da fonte de luz incidente sob as máscaras também não interferiram nos julgamentos em centímetros da sua profundidade ou relevo. Resultados semeIhantes foram obtidos por Quaglia e Fukusima (2009) com máscaras côncavas observadas monocularmente em uma câmara escura e por Quaglia et al. (2014) com máscaras côncavas objetivas posicionadas dentro de uma caixa. No entanto, as médias da profundidade métrica atribuída pelos observadores foram maiores para a máscara convexa objetiva. Comparativamente à máscara convexa, as máscaras côncavas foram percebidas como mais rasas. Esses resultados corroboram os obtidos por Hartung et al. (2005) e Hartung et al. (2001). Esses autores deduziram que a máscara côncava era percebida com menor profundidade que a máscara convexa, ao solicitar dos participantes a atribuição da distância percebida entre eles e os alvos localizados nas projeções das máscaras côncava e convexa.

\section{Considerações finais}

Os resultados encontrados na presente pesquisa corroboram a sobreposição dos processos cognitivos, top-down, sobre os sensoriais, bottom-up, durante a observação da máscara côncava. A maioria dos participantes percebeu a ilusão da máscara côncava a despeito das alterações da direção da fonte de iluminação e do posicionamento da máscara. De forma semelhante, as atribuições métricas e categóricas da profundidade ou relevo percebido não foram influenciadas pelas variações nas condições de observação. Até mesmo as atribuições de planura à máscara côncava demonstraram uma tendência para a realização da inversão visual da profundidade da máscara côncava, especialmente quando consideramos que, mesmo classificando-a como plana, a maioria dos indivíduos atribuiu-lhe um relevo. A máscara convexa foi percebida como tal na grande maioria das vezes e recebeu as maiores estimativas métricas de relevo, apesar desta diferença não ser estatisticamente significativa. Tais resultados se mostram relevantes na confirmação da estabilidade na percepção de faces tridimensionais além de corroborarem o processamento top-down na percepção do fenômeno ilusório da máscara côncava.

\section{Referências}

Darwin, C. (1874). The descent of man and selection in relation to sex ( $2^{\mathrm{a}}$ ed.). Londres: John Murray.

Gregory, R. L. (1997). Knowledge in perception and illusion. Philosophical Transactions of the Royal Society B: Biological Sciences, 352(1358), 1121-1128. doi: 10.1098/rstb.1997.0095

Hartung, B., Franz, V. H., Kersten, D., \& Bülthoff, H. H. (2001). Is the motor system affected by hollow-face illusion? Journal of Vision, 1(3), 256. doi:10.1167/1.3.256-274

Hartung, B., Schrater, P. R., Bülthoff, H. H., Kersten, D., \& Franz, V. H. (2005). Is prior knowledge of object geometry used in visually guided reaching? Journal of Vision, 5, 504-514. doi:10.1167/5.6.2

Hill, H., \& Bruce, V. (1993). Independent effects of lighting, orientation, and stereopsis on the hollow-face illusion. Perception, 22(8), 887897. doi:10.1068/p220887

Hill, H., \& Johnston, A. (2007). The hollow-face illusion: object-specific knowledge, general assumptions or properties of the stimulus. Perception, 36(2), 199-223. doi: 10.1068/p5523. 
Keane, B. P., Silverstein, S. M., Wang, Y., \& Papathomas, T. V. (2013). Reduced depth inversion illusions in schizophrenia are state-specific and occur for multiple object types and viewing conditions. Journal of Abnormal Psychology, 122(2), 506. doi: 10.1037/a0032110

Kleffner, D. A., \& Ramachandran, V. S. (1992). On the perception of shape from shading. Perception \& Psychophysics, 52(1), 18-36. doi: $10.7717 /$ peerj.363

Ministério da Saúde (2008). Projeto olhar Brasil: triagem de acuidade visual: manual de orientação. Brasília: Ministério da Saúde e Ministério da Educação. Recuperado de http://portal.mec.gov.br/index.php?option=com_docman\&view=download\&alias=1863-pse-manual-olharbrasil\&category_slug=novembro-2009-pdf\&ltemid=30192

Quaglia, M. A. C., Bachetti, L. D. S., \& Alves, A. (2014). The hollow-face illusion monocularly observed in a box. Estudos de Psicologia, 31(3), 359-366. doi:10.1590/0103-166x2014000300004

Quaglia, M. A. C., \& Fukusima, S. S. (2009). Cor, iluminação e orientação do reverso de uma máscara facial não afetam a ilusão da máscara côncava. Estudos de Psicologia, 14(2), 97-105. doi:10.1590/ S1413-294X2009000200002
Quaglia, M. A. C., \& Fukusima, S. S. (2015). Efeitos da cor, iluminação e rotação na ilusão estereoscópica da máscara côncava. Psicologia: Reflexão e Crítica, 28(2), 213-221. doi:10.1590/1678-7153.201528219

Resolução no 196 do Conselho Nacional de Saúde (1996, 10 de outubro). Dispõe sobre diretrizes e normas regulamentadoras de pesquisas envolvendo seres humanos. Brasília, DF: Ministério da Saúde. Recuperado de http://bvsms.saude.gov.br/bvs/saudelegis/ cns/1996/res0196_10_10_1996.html

Vlajnic, V. M., Papathomas, T. V., Keane, B. P., Zalokostas, A., \& Silverstein, S. M. (2014). What's in a face? The role of depth undulations in three-dimensional depth-inversion illusions. Perception, 43(5), 381-394. doi: 10.1068/p7632

Yoshida, H. (2006). The effects of facial texture, stimulus orientation and light direction on the hollow-face illusion. Bulletin of the Graduate School of Education, Hiroshima University, Education and Human Science, 55, 321-329. Recuperado de http://ir.lib. hiroshimau.ac.jp/files/public/18574/20141225135145292103/ AA11625039_55_321.pdf

Esther Sampaio Santos, Mestre em Psicologia, linha de pesquisa em Saúde Mental, Universidade Federal de São João Del-Rei (UFSJ), é Doutoranda em Applied Health Science, linha de pesquisa Behavioural and Population Health, Brock University, Canadá. Endereço para correspondência: 64 Roehampton Avenue, Apt 216, ON L2M7P5, St. Catharines, Canadá. Telefone: +1 (289) 501-6538. E-mail: esther.sampaio2@yahoo.com.br

Lívia da Silva Bachetti, Mestre em Psicologia, linha de pesquisa em Saúde Mental, Universidade Federal de São João Del-Rei (UFSJ), é Doutoranda em Psicobiologia, linha de pesquisa em Percepção Visual: Percepção de tamanho e do espaço, Universidade de São Paulo (USP). E-mail: livbachetti@yahoo.com.br

Maria Amélia Cesari Quaglia, Doutora em Psicobiologia, Universidade de São Paulo (USP), é Docente no Programa de Pós-graduação em Psicologia, Universidade Federal de São João Del-Rei (UFSJ).

E-mail: melinha@ufsj.edu.br

Caio Rafael Silveira, Graduado em Psicologia, Universidade Federal de São João Del-Rei (UFSJ), é Psicólogo no Centro de Referência de Assistência Social (CRAS) do município de Baependi (MG).

E-mail: caio-rafael-@hotmail.com

Branda Garcia da Silva, Graduada em Psicologia, Universidade Federal de São João Del-Rei (UFSJ), é Psicóloga no Centro de Referência de Assistência Social (CRAS) do município de Baependi (MG).

E-mail: branda.cax@gmail.com

Recebido em 16.Ago.15 Revisado em 01.Out.16 Aceito em 04.Abr.17 